Ärztliche Erfahrung beschränkt sich nicht auf medizinisches Fachwissen. Sie entsteht auch aus den mehr oder minder alltäglichen, heiter, ärgerlich oder nachdenklich stimmenden Erlebnissen mit Patienten, Kollegen und Mitarbeitern. Senden Sie uns Ihre Geschichte an: Brigitte.Moreano@springer.com. Für jeden veröffentlichten Text erhalten Sie bis zu 100 Euro.

\title{
Darum bin ich Migrant
}

- Es ist eines der großen Rätsel dieser Welt, wie es plötzlich zur Migration, d. h. der periodisch wiederkehrenden Massenbewegung aller oder viele Individuen einer Tierart kommt. Nichts hat mich mehr beeindruckt als die Migration zehntausender Gnus, Zebras, Gazellen und Büffel in der Serengeti miterleben zu dürfen. Wahrscheinlich ist die Bereitschaft zum Zusammenschluss der Tiere zur Wanderung genetisch festgelegt.

Möglicherweise ist dieser Wandertrieb auch bei mir rudimentär ausgebildet, denn nach einer gewissen Zeit verspüre ich - wie die Seelachse - ebenfalls ein großes Verlangen, an die Wiege meiner Kindheit zurückzukehren.

Haben die Tiere auf ihren Wanderungen bisweilen mit Störungen im Magnetfeld der
Erde oder mit Auswirkungen eines Klimawandels zu kämpfen, so liegt das Problem bei mir in der Auswahl des Fortbewegungsmittels. Egal, ob man Auto, Flugzeug oder Eisenbahn benutzt, es gibt ständig wiederkehrende Störungen.

Allein schon die Hotelreservierung erweist sich bei mir als problematisch, insbesondere was Übermittlungsfehler bei der Kreditkartennummer oder Fehler bei Anreise oder Abreisetag etc. anbetrifft. Daher frage ich mich, was mag wohl die Ursache für meinen neuerlichen Wandertrieb sein? Obwohl eine gewisse Übereinstimmung mit dem Migrationsverhalten der Tiere nicht von der Hand zu weisen ist, gingen meine weiteren Recherchen dahingehend ins Leere. Plötzlich hatte ich aber einen Gedanken, der mich nicht mehr losließ.
Könnte mein Bestreben zur Migration mit einem unterschwelligen Fluchtvorhaben aus Angst vor einer Zwangsrekrutierung durch die Standesorganisation in Verbindung gebracht werden, die jetzt bekanntermaßen die Lücken in der Versorgung ländlicher Gebiete mit Ärzten durch die Mobilisierung von ärztlichen Ruheständler zu schließen sucht? Ganz von der Hand zu weisen ist der Gedanke nicht, denn nicht umsonst bietet die Standesorganisation Fortbildungsveranstaltungen für vormals entsorgte Altmediziner an, damit diese fortbildungsmäßig aufgepeppt den Fehlbestand an Ärzten, zumindest vorübergehend, auffüllen können und wieder in die Rolle eines Albert Schweizter schlüpfen sollen oder dürfen.

DR. MED. UDO FUCHS -

\section{Radeberger statt Lithium}

— Freitag, zeitiger Nachmittag. Ich hatte Bereitschaftsdienst. Da rief mich der Leiter des Stadtcafé am Markt einer kleinen Oberlausitzer Kreisstadt an und teilte mir mit, dass in seiner Gaststube ein Mann aufgetreten sei, der dort einen Kasten echtes Radeberger Export-Pilsner kaufen wollte. Dieses besonders gute Bier gab es nur in besonderen Läden, Gaststätten und für besondere Personen.

Er sei Arzt, habe einen Patienten, einen hochrangigen Genossen und VdN (Verfolgten des Naziregimes), mit Harnverhaltung in Behandlung, der nur nach Genuss dieser speziellen Biersorte urinieren könne. Als ihm das Bier verweigert wurde, sei der
Arzt laut geworden und habe drastisch die Symptome und möglichen Folgen der Harnverhaltung und der Überlaufinkontinenz geschildert, und das coram publico und mit ordinären Worten, was bei den Gäs-

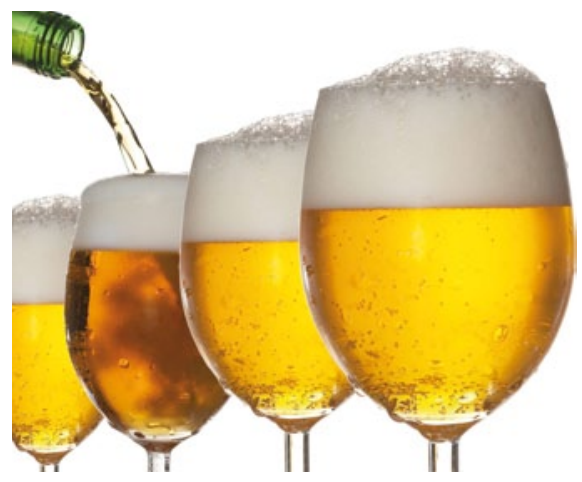

ten zunächst Heiterkeit, bald aber Empörung auslöste.

Zur Vermeidung größeren Aufsehens habe der Leiter des Stadtcafés dann einen Kasten „Radeberger Export” herausgerückt. Nun wollte er von mir wissen, ob das tatsächlich ein Arzt gewesen sei.

Ich konnte ihn beruhigen. Der Kollege litt an einer manisch-depressiven Krankheit und war unter Lithiumbehandlung weitgehend unauffällig. Manchmal kam er aber auf die Idee, dieses Medikament nicht mehr zu benötigen. Und dann kam es immer wieder sehr bald zu den sonderbarsten Vorkommnissen.

DR. MED. E. TÖPPICH, ULLERSDORF ॥ 